\title{
The 16th Summer Intensive Course \& the EACON 2018
}

\author{
Sangil Suh, $\mathrm{MD}^{1}$, Byung Moon Kim, $\mathrm{MD}^{2}$ \\ ${ }^{1}$ Department of Radiology, Korea University Guro Hospital, Seoul, Korea \\ ${ }^{2}$ Department of Radiology, Severance Hospital, Seoul, Korea
}

The 16th Summer Intensive Course of the Korean Society of Interventional Neuroradiology was held at Busan Lotte Hotel on August 24 (Friday), 2018 (Fig. 1). The total number of participants was 461 in the conference which was also open for foreign doctors to join the East Asian Conference of Neurointervention on the next day. There were 373 Koreans and 88 foreigners who attended from 12 different countries (China, Germany, Hong Kong, Indonesia, Japan, Korea, Malaysia, Singapore, Taiwan, Thailand, USA, and Vietnam). The program featured scientific sessions dedicated to advances in neurointervention and difficult case discussions (Fig. 2). Some of the main program was as below.

Special Lecture. Commemorative Lecture by Founding Members

\begin{tabular}{lc}
\hline Subject & Speaker \\
\hline My long journey as a Neurointerventionist & Dong Ik Kim \\
Wonderful memories with KSIN & (CHA University) \\
& Nam Joon Lee \\
(Korea University)
\end{tabular}

\section{Invited Speaker}

\begin{tabular}{lc}
\hline Subject & Speaker \\
\hline $\begin{array}{l}\text { The embolization with Onyx }{ }^{\text {TM }} \text { liquid embolic system: } \\
\text { Treatment of brain AVMs and complication management }\end{array}$ & $\begin{array}{c}\text { Hannes Nordmeyer } \\
\text { (Radprax MVZ GmbH } \\
\text { Solingen, Germany) }\end{array}$ \\
DAWN trial & $\begin{array}{c}\text { Raul G. Nogueira } \\
\text { (Emory University, USA) }\end{array}$ \\
$\begin{array}{l}\text { Establishment of stroke center in Korea } \\
\text { Ji Hoe Heo } \\
\text { Mid-term plan of cardiovascular disease and stroke } \\
\text { management Policy in Korea }\end{array}$ & Haerae Kim \\
\end{tabular}

Best Case of the Summer Award (Two best cases of 12 case presentations were awarded)

\begin{tabular}{lc}
\hline Subject & Speaker \\
\hline $\begin{array}{l}\text { Life-threatening hemorrhage of mandibular arteriovenous } \\
\text { malformation (AVM) treated with transarterial }\end{array}$ & $\begin{array}{c}\text { Junhwee Kim } \\
\text { (Yonsei University) }\end{array}$ \\
$\begin{array}{l}\text { and transvenous embolization } \\
\text { dissection with multiple overlapping PEDs }\end{array}$ & $\begin{array}{l}\text { Soon Chan Kwon } \\
\text { (University of Ulsan) }\end{array}$ \\
\hline
\end{tabular}

\author{
Correspondence to: \\ Sangil Suh, MD \\ Department of Radiology, Korea \\ University Guro Hospital, 148 Guro- \\ dong-ro, Guro-gu, Seoul 08308, Korea \\ Tel: +82-2-2626-1339 \\ Fax: +82-2-863-9282 \\ E-mail: sangil.suh@gmail.com
}

Copyright $\odot 2018$ Korean Society of Interventional Neuroradiology

This is an Open Access article distributed under the terms of the Creative Commons Attribution Non-Commercial License (http://creativecommons.org/licenses/by-nc/3.0) which permits unrestricted non-commercial use, distribution, and reproduction in any medium, provided the original work is properly cited. 


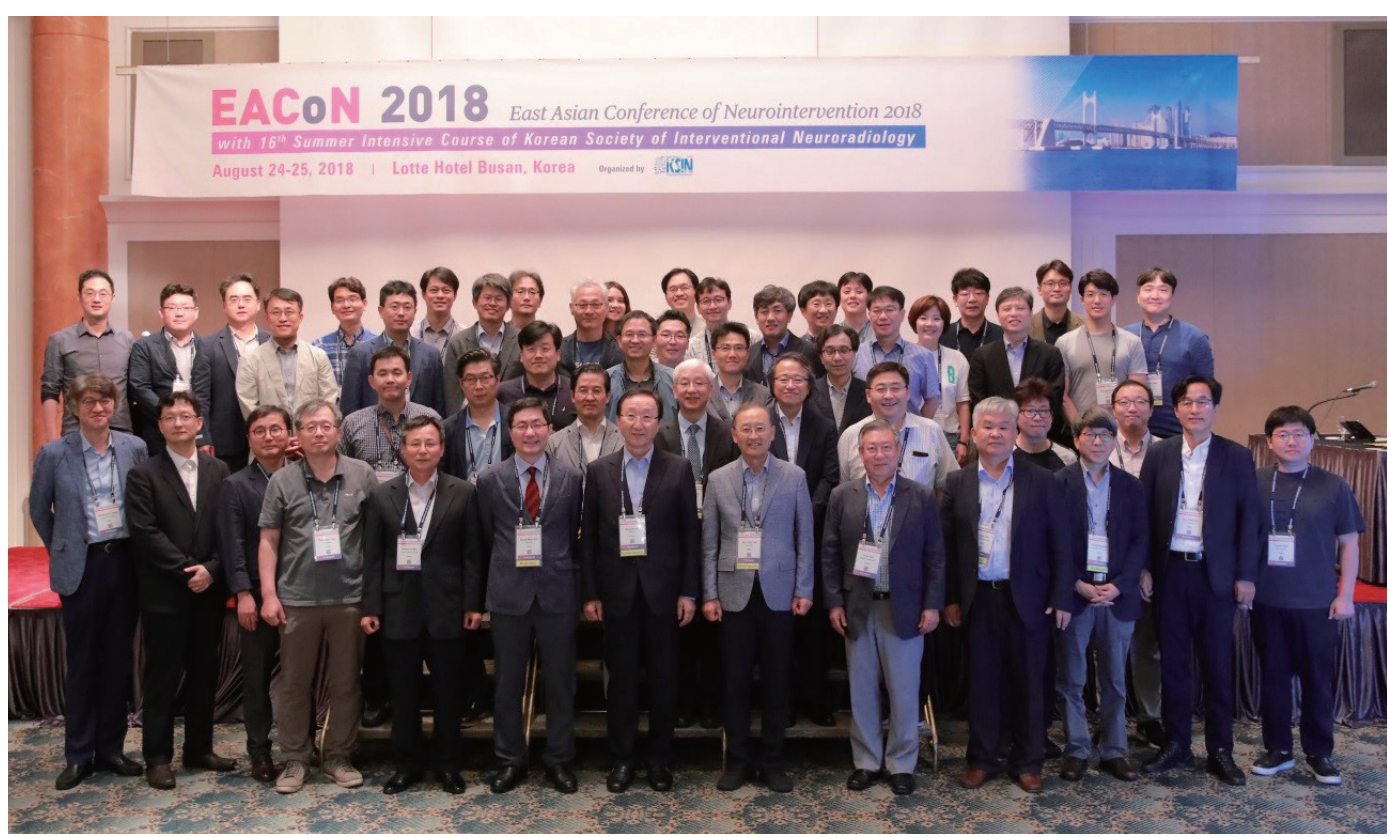

Fig. 1. A photo of executive committee members, guest speakers and some participants during the summer intensive course 2018.

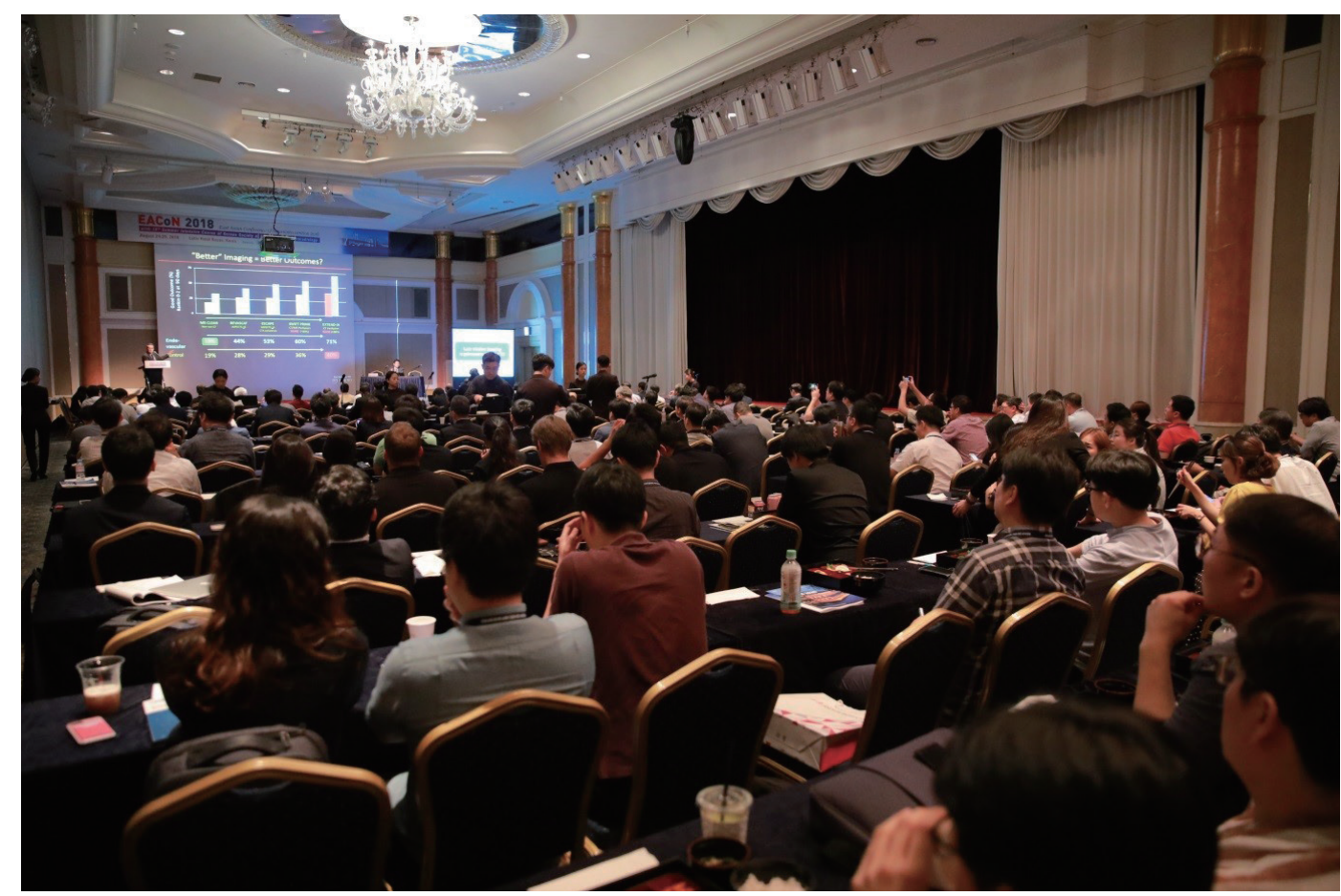

Fig. 2. Scientific session during the summer intensive course 2018. 